\title{
lncRNA TNXA-PS1 Modulates Schwann Cells by Functioning As a Competing Endogenous RNA Following Nerve Injury
}

\author{
Chun Yao, ${ }^{1 *}$ - Yaxian Wang, ${ }^{1 *}$ Honghong Zhang, ${ }^{1 *}$ Wei Feng, ${ }^{1}$ Q Q Qihui Wang, ${ }^{1}$ Dingding Shen, ${ }^{1}$ Tianmei Qian, ${ }^{1}$ \\ Fang Liu, ${ }^{1}$ Susu Mao, ${ }^{1}$ Xiaosong Gu, ${ }^{1,2}$ and ${ }^{1}$ Bin Y $\mathbf{u}^{1,2}$ \\ ${ }^{1}$ Key Laboratory of Neuroregeneration of Jiangsu and Ministry of Education, Co-innovation Center of Neuroregeneration, Nantong University, Nantong \\ 226001, China and 2Jiangsu Clinical Medicine Center of Tissue Engineering and Nerve Injury Repair, Affiliated Hospital of Nantong University, Nantong \\ University, Nantong 226001, China
}

As the major glia in PNS, Schwann cells play a critical role in peripheral nerve injury repair. Finding an efficient approach to promote Schwann cell activation might facilitate peripheral nerve repair. Long noncoding RNAs (lncRNAs) have been shown to regulate gene expression and take part in many biological processes. However, the role of lncRNAs in peripheral nerve regeneration is not fully understood. In this study, we obtained a global lncRNA portrayal following sciatic nerve injury in male rats using microarray and further investigated one of these dys-regulated lncRNAs, TNXA-PS1, confirming its vital role in regulating Schwann cells. Silencing TNAX-PS1 could promote Schwann cell migration and mechanism analyses showed that TNXA-PS1 might exert its regulatory role by sponging miR-24-3p/miR-152-3p and affecting dual specificity phosphatase 1 (Dusp1) expression. Systematic lncRNA expression profiling of sciatic nerve segments following nerve injury in rats suggested lncRNA TNXA-PS1 as a key regulator of Schwann cell migration, providing a potential therapeutic target for nerve injury repair.

Key words: competing endogenous RNA; long noncoding RNA; migration; peripheral nerve injury; Schwann cell

Significance Statement

The PNS has an intrinsic regeneration capacity after injury in which Schwann cells play a crucial role. Therefore, further exploration of functional molecules in the Schwann cell phenotype modulation is of great importance. We have identified a set of dys-regulated long noncoding RNAs (lncRNAs) in rats following sciatic nerve injury and found that the expression of TNXA-PS1 was significantly downregulated. Mechanically analyses showed that TNXA-PS1 might act as a competing endogenous RNA to affect dual specificity phosphatase 1 (Dusp1) expression, regulating migration of Schwann cells. This study provides for the first time a global landscape of lncRNAs following sciatic nerve injury in rats and broadens the known functions of lncRNA during nerve injury. The investigation of TNXA-PS1 might facilitate the development of novel targets for nerve injury therapy.

\section{Introduction}

Peripheral nerve injury could result in severe sensory and motor dysfunction by damaging the integrity of axon and Schwann cells,

\footnotetext{
Received Dec. 10, 2016; revised June 9, 2018; accepted June 11, 2018

Author contributions: X.G. and B.Y. designed research; C.Y., Y.W., H.Z., W.F., Q.W., T.Q., F.L., and S.M. performed research; C.Y., Y.W., H.Z., and B.Y. analyzed data; C.Y. and B.Y. wrote the paper; D.S. edited the paper.

This work was supported by National Major Project of Research and Development (Grant 2017YFA0104701 to B.Y.), the National Key Basic Research Program of China (Grant 2014CB542202 to X.G.), the National Natural Science Foundation of China (Grant 31730031 to X.G., Grant 31371062 to B.Y., and Grant 31500823 to C.Y.), Jiangsu Provincial Natural Science Foundation (Grant BK20150403 to C.Y.), the Basic Research Program of Jiangsu Education Department (Grant 15KJA180007 to B.Y.), and Jiangsu Provincial Key Medical Center and Priority Academic Program Development of Jiangsu Higher Education Institutions (PAPD).

The authors declare no competing financial interests.

${ }^{*}$ C.Y., Y.W., and H.Z. contributed equally to this work.

Correspondence should be addressed to Xiaosong Gu or Bin Yu, Key laboratory of neuroregeneration of Jiangsu and Ministry of Education, Co-innovation Center of Neuroregeneration, Nantong University, Nantong 226001, China.E-mail: nervegu@ntu.edu.cn or yubin@ntu.edu.cn.
}

affecting the quality of life (Wu and Murashov, 2013; Cheng et al., 2015). Although the traditional microsurgical approach may restore nerve continuity, limitations exist in nerve regeneration and functional recovery because of an insufficient understanding of neurobiology following peripheral nerve injury (Yu et al., 2015). Nerve regeneration is a complex biological process, orchestrated by multiple cells, growth factors, and extracellular matrix (Tang et al., 2013). Schwann cells, the major glia cells in PNS, provide a suitable microenvironment for nerve regeneration (da Silva et al., 2014). Following axonal degeneration by nerve injury, Schwann cells undergo a series biological processes, including dedifferentiation, proliferation, migration, removal of myelin debris, secretion of neurotrophic factors, and remyelination, facilitating nerve regeneration (Heinen et al., 2013). Schwann cell migration 
can precede and enhance axonal repair by guiding axon reinnervation and controlling synaptic formation (Son et al., 1996; Torigoe et al., 1996; Forciniti et al., 2014).

With the development of high-throughput sequencing and array-based technologies, various kinds of noncoding RNAs (ncRNAs) have been identified. One major class of ncRNAs is long noncoding RNAs (lncRNAs), which are long transcripts $(>200 \mathrm{nt}$ ) without obvious protein-coding potential (Geisler and Coller, 2013). Although many lncRNAs may be transcriptional noise, a growing number of lncRNAs have been reported to have biological functions. They could regulate various biological processes, including dosage compensation, genomic imprinting, cell cycle, differentiation, and development, at the epigenetic, transcriptional, and posttranscriptional levels (Wilusz et al., 2009; Chen and Carmichael, 2010; Yang et al., 2014). In addition, the dysregulation of lncRNAs appears to be involved in many diseases, especially in cancers (Xiang et al., 2014; Zhang et al., 2014). Emerging evidence highlights that lncRNAs are expressed in CNS and mediate neural cell activities, contributing to various CNS pathologies (Qureshi et al., 2010). However, the specific roles of lncRNAs in peripheral nerve injury, especially in Schwann cell phenotype modulation, are not well studied.

Our group has previously identified altered lncRNA expression in dorsal root ganglia (DRG) after sciatic nerve injury and found IncRNA uc.217 could affect neurite outgrowth in DRG neurons (Yu et al., 2013; Yao et al., 2015). Recently, Pan et al. (2017) reported time-dependent lncRNA alteration in mice by microarray. However, they did not fully explore the functions and mechanisms underlying certain lncRNAs. Here, we performed microarray aiming at detecting lncRNA expression alteration in sciatic nerve segment after sciatic nerve crush injury in rats and selected one specific lncRNA TNXA-PS1 for further investigation. We confirmed the downregulation of lncRNA TNXA-PS1 following peripheral nerve injury and found that silencing lncRNA TNXA-PS1 in Schwann cells could promote Schwann cell migration. Investigation of the mechanism responsible for this showed that lncRNA TNXA-PS1 might exert this role by competing with miRNAs to regulate the expression of dual specificity phosphatase 1 (Dusp1) in Schwann cells, providing a novel mechanism and a potential therapeutic target for peripheral nerve injury.

\section{Materials and Methods}

Animal surgery and tissue preparation. Twenty-four adult, male Sprague Dawley (SD) rats (180-220 g) were randomly divided into four groups of six rats each. All animals underwent surgery of sciatic nerve crush injury. Briefly, the sciatic nerve at $10 \mathrm{~mm}$ above the bifurcation into the tibial and common fibular nerves was crushed with a forceps at a force of 54 $\mathrm{N}$ for 3 times (a period of $10 \mathrm{~s}$ for each time). The proximal stumps of sciatic nerve $(0.5 \mathrm{~cm})$ were collected at $0,1,4$, and $7 \mathrm{~d}$ after injury, respectively. The experiment was repeated three times. All the experimental procedures involving animals were conducted in accordance with institutional animal care guidelines and were approved ethically by the Administration Committee of Experimental Animals, Jiangsu Province, China.

RNA extraction, microarray, and bioinformatic analyses. Total RNA was extracted from the sciatic nerve segment using TRIzol (Invitrogen) and RNA cleanup including a DNase I digestion step was performed using RNeasy spin columns (Qiagen). Total RNA from each sample was quantified using the Nano Drop 1000. We used the Array platform (Agilent Technologies) for microarray analyses. The sample preparation and microarray hybridization were performed based on the manufacturer's standard protocols as described previously (Yu et al., 2013). lncRNA and mRNA expression profiles were compared and differentially expressed genes were screened for different time points. The differentially expressed lncRNAs then underwent hierarchical clustering and expression pattern clustering analyses (Liao et al., 2011; Yu et al., 2013). In hierarchical clustering, the $Z$ score was calculated from the expression of lncRNAs and the Euclidean distance measure was used to compute the distance (dissimilarity) in lncRNA and time. In expression pattern clustering, the significance analysis of expression tendency was screened for differentially expressed lncRNAs. Using a strategy for clustering shorttime-series gene expression data, we defined some unique profiles. The expression model profiles are related to the actual or the expected number of genes assigned to each model profile. Significant profiles have higher probability than expected by Fisher's exact test and multiplecomparisons test.

A gene coexpression network was built according to the normalized signal intensity of specific expression lncRNAs and mRNAs (Liao et al., 2011). Gene ontology (GO) and KEGG (Kyoto Encyclopedia of Genes and Genomes) enrichment analyses were performed to elucidate biological processes and signaling pathways associated with the correlated targets of specific lncRNAs.

$q R T-P C R$. RNA samples were reverse transcribed to cDNA with the Prime-Script RT reagent Kit (TaKaRa). qRT-PCR was performed with SYBR Premix Ex Taq (TaKaRa) on an ABI Stepone system (Applied Biosystems) according to standard protocols in triplicate for each sample. The relative expression level was calculated using the comparative $2^{-\Delta \Delta \mathrm{Ct}}$ method.

In situ hybridization. Digoxigenin (DIG)-labeled rat lnc TNXA-PS1 probes were synthesized using the DIG RNA Labeling Kit (Roche). After treatment with proteinase $\mathrm{K}$, the acetylated sciatic nerve segment sections were prehybridized for $2 \mathrm{~h}$ and then hybridized with DIG-labeled probes overnight at $37^{\circ} \mathrm{C}$ in a humid chamber. The sections were then blocked with AKP-conjugated Fab anti-DIG antibody (Roche) overnight at $4^{\circ} \mathrm{C}$ and stained by 5-bromo-4-chloro-3-indolyl phosphate and nitroblue tetrazolium (Roche) for visualization and imaging.

$5^{\prime}$ and $3^{\prime}$ rapid amplification of cDNA ends (RACE) analysis. RACE analyses were performed with total RNA extracted from sciatic nerve tissues using the SMART RACE cDNA amplification kit (Clontech) according to the manufacturer's instructions. The RACE products were cloned into pGM-T vector (Tiangen Biotech) and sequenced.

Northern blotting. Northern blot was performed with the Dig Northern Starter Kit (Roche). Briefly, DIG-labeled rat lnc TNXA-PS1 probes were synthesized. Total RNA $(10 \mu \mathrm{g})$ of sciatic nerve segment tissues was subjected to formaldehyde gel electrophoresis and transferred onto a nylon membrane. After being prehybridized with northern blot hybridized buffer for $3 \mathrm{~h}$, the membranes containing RNA were incubated with the labeled denatured probes at $60^{\circ} \mathrm{C}$ overnight. The following day, membranes were washed and detected.

Primary culture of Schwann cells and cell transfection. Schwann cells were isolated from sciatic nerves of 1-d-old SD rats and treated to remove the fibroblasts using anti-Thy1.1 antibody (Sigma-Aldrich) and rabbit complement (Invitrogen) as described previously (Mantuano et al., 2008). The final cell preparation consisted of $98 \%$ Schwann cells, as determined by immunostaining with the specific Schwann cell marker S100 $\beta$. Primary culture of Schwann cells was maintained in DMEM containing $10 \%$ fetal bovine serum (complete medium) at $37^{\circ} \mathrm{C}$ under humidified $5 \% \mathrm{CO}_{2}$. The cell culture was passaged no more than three times before the following tests.

Primary cultured Schwann cells were transfected with lnc TNXA-PS1 or Dusp1 siRNAs (Ribobio) with Lipofectamine RNAiMAX transfection reagent (Invitrogen). Schwann cell migration was examined using the Transwell migration assay as described previously (Mantuano et al., 2008). Transwell chambers ( $6.5 \mathrm{~mm}$ with $8 \mu \mathrm{m}$ pores; Costar) and the bottom surface of each membrane was precoated with $10 \mu \mathrm{g} / \mathrm{ml} \mathrm{fi-}$ bronectin. Briefly, Schwann cells in DMEM $\left(100 \mu \mathrm{l}, 10^{6}\right.$ cells $\left./ \mathrm{ml}\right)$ were transferred to the top chamber of the Transwell and $600 \mu$ l of complete medium was injected into the lower chamber. After incubating at $37^{\circ} \mathrm{C}$ in $5 \% \mathrm{CO}_{2}$ for $24 \mathrm{~h}$, the upper surface of each membrane was cleaned with a cotton swab and cells adhering to the bottom surface were stained with $0.1 \%$ crystal violet. Each bottom surface was then imaged with $>5$ views 
and counted with a DMR inverted microscope (Leica Microsystems). Assays were performed three times using triplicate wells.

Isolation of cytoplasmic and nuclear RNA. Cytoplasmic and nuclear RNA of Schwann cells were isolated and purified using the PARIS Kit (Life Technologies) according to the manufacturer's instructions. The relative expression of lnc TNXA-PS1 in each fraction was then detected by qRT-PCR.

FISH. FISH for lnc TNXA-PS1 was conducted on 4\% PFA-fixed slides with monolayers of Schwann cells using a DIG-labeled probe at $1 \mu \mathrm{g} / \mathrm{ml}$ concentration. Hybridization was performed at $42^{\circ} \mathrm{C}$ overnight, followed by incubating with anti-DIG antibody and secondary antibody. Slides were subsequently counterstained using Hoechst and observed under a microscope.

Competing endogenous RNA (ceRNA) target gene prediction. We used an approach termed mutually targeted miRNA response element (MRE) enrichment (MuTaME), as described previously (Tay et al., 2011), to search possible target genes of TNXA-PS1 as ceRNA. Briefly, MuTaME evaluates a candidate ceRNA target genes based on the number of miRNAs and the MREs shared by the target genes and TNXA-PS1. This bioinformatic analysis was conducted by rna 22 microRNA target prediction algorithm (Miranda et al., 2006) to generate MuTaME scores (KangChen Bio-tech).

Luciferase reporter assay. The 3'-UTR sequence of Plxna3, Dusp1, Slit1, and the full length of TNXA-PS1 were constructed into pmirGLO vector and cotransfected with certain miRNAs into 293T cells. The relative luciferase activity was normalized to Renilla luciferase activity $48 \mathrm{~h}$ after transfection.

Western blot analysis. Protein extracts were prepared from primary cultured Schwann cells. Equal amounts of protein were electrophoresed on $10 \%$ SDS-PAGE and then transferred onto a nitrocellulose membrane (Bio-Rad). Blots were probed with antibody against Dusp1 (Abcam). In vivo tests for Schwann cell migration. The in vivo Schwann cell migration was analyzed as described previously (Zhou et al., 2014). A silicone conduit (inner diameter $1.0 \mathrm{~mm}$ ) was inserted into the $5 \mathrm{~mm}$ sciatic nerve gap between the proximal and distal stumps in a rat sciatic nerve transection model. Cy5-labeled lnc TNXA-PS1 siRNA or control (Ribobio) mixed with Matrigel (1:1 v/v) (BD Biosciences) was slowly injected into the conduit lumen using a precooled micropipette. The surgical incision was closed in a routine fashion and animals were housed in large cages with sawdust bedding to minimize the discomfort and possible painful mechanical stimulation.

At $10 \mathrm{~d}$ after surgery, rats were killed and the silicon conduits containing regenerated nerves were collected. The migration of Schwann cells and axon outgrowth were observed by immunostaining with anti-Sox10 (CST) and anti- $\beta$-tubulin III antibody (Sigma-Aldrich), respectively.

Statistical analysis. All data are presented as means \pm SEM. Statistical comparison was performed with Student's $t$ test using Prism 5 software (GraphPad). $p<0.05$ was considered statistically significant.

\section{Results \\ lncRNA expression profile in sciatic nerve after sciatic nerve injury}

Following sciatic nerve crush injury, the sciatic nerve underwent degeneration with much axon and Schwann cell debris as shown by electron microscopic and immunohistochemistry analysis (Fig. 1 $A, B$ ). After sciatic nerve injury, the layers of myelin sheath were condensed as normal in $1 \mathrm{~d}$. However, at $4 \mathrm{~d}$, sciatic nerve degenerated with the loosening of myelin sheath structure. Up to $7 \mathrm{~d}$, the regenerated axons were remyelinated by Schwann cells. Rat sciatic nerve segments were then collected at $0,1,4$, and $7 \mathrm{~d}$. Using Arraystar Rat lncRNA microarray, we obtained a global landscape of lncRNAs and mRNAs following sciatic nerve injury, among which there was a total of 758 differentially expressed lncRNAs and 1387 mRNAs. Hierarchical clustering showed systematic variations in the expression of these lncRNAs at various time points and indicated that these lncRNA expression could be divided into two groups, Group 1 ( 0 and $1 \mathrm{~d}$ ) and Group 2 (4 and
7 d) (Fig. 1C), which may represent the preregeneration phase and regeneration phase, respectively. We then summarized lncRNA expression with 26 model profiles. Among these, there were six profiles with significant $p$-values for expression tendency (Fig. 1D). Profile 1 contained 124 differentially expressed lncRNAs, which were downregulated following nerve injury (Fig. $1 E)$. A gene coexpression network was constructed to cluster 124 lncRNAs of profile 1 and coding mRNA, suggesting that 268 coding mRNAs were coexpressed, positively or negatively, with these 124 lncRNAs during the time course (Fig. $1 F$ ). GO analysis for the coexpressed 268 coding genes showed that the biological processes of these genes were enriched in cell adhesion and regulation of cytoskeleton, suggesting that cell migration might change (Table 1).

\section{lnc TNXA-PS1 expression and characteristics}

We then chose one of the lncRNAs in profile 1, NR_024118 (lnc TNXA-PS1, tenascin XA, pseudogene 1), for further validation. Consistent with our microarray analysis, lnc TNXA-PS1 was downregulated following nerve injury as detected by qRT-PCR (Fig. $2 A, 0$ d: $0.216 \pm 0.0106 ; 1 \mathrm{~d}: 0.131 \pm 0.012, p=0.0057$ vs $0 \mathrm{~d}$; $4 \mathrm{~d}: 0.074 \pm 0.001, p=0.0002$ vs $0 \mathrm{~d} ; 7 \mathrm{~d}: 0.107 \pm 0.014, p=$ 0.0033 vs $0 \mathrm{~d} ; n=3$ for each group, Student's $t$ test). In situ hybridization further indicated the downregulation of $\operatorname{lnc}$ TNXA-PS1 expression in Schwann cells at $4 \mathrm{~d}$ after sciatic nerve injury (Fig. 2B).

To investigate the functions and molecular mechanism of lncRNAs, a full length of the certain lncRNA is essential. Therefore, we tried to obtain the full sequence of TNXA-PS1 by RACE experiment and found that lnc TNXA-PS1 was $1548 \mathrm{nt}$ in length (Fig. 2C). This transcript was located on chromosome 20p12 and comprised 11 exons, as shown in the USCS Genome Browser (Fig. 2D). Northern blots also revealed that the full-length of lnc TNXA-PS1 was $\sim 1500 \mathrm{nt}$ and was expressed stably in sciatic nerve segments (Fig. 2E).

We then isolated cytoplasmic and nuclear RNA from primary cultured Schwann cells and detected TNXA-PS1 expression in each fraction by qRT-PCR. The results shown that, compared with U6 (mostly expressed in nuclear) and actin (mostly expressed in cytoplasm), TNXA-PS1 is mainly expressed in cytoplasm (Fig. 2F, TNXA-PS1-nuclear: $22.5 \pm$ 3.66; TNXA-PS1-cytoplasm: $77.5 \pm 3.66$; actin-nuclear: $20.6 \pm 0.445$; actin-cytoplasm: $79.4 \pm 0.445$; U6-nuclear: $50 \pm$ 3.98; U6-cytoplasm: $50 \pm 3.98 ; n=3$ for each group). Further FISH experiments on Schwann cells also confirmed the mainly cytoplasm localization of TNXA-PS1 (Fig. 2G).

\section{Silencing of lnc TNXA-PS1 promotes Schwann cell migration both in vitro and in vivo}

Specific TNXA-PS1 siRNAs were transfected into Schwann cells to explore the role of lnc TNXA-PS1 on Schwann cells. The mRNA expression of lnc TNXA-PS1 could be reduced significantly by both siRNA1 and siRNA2 to $\sim 40 \%$ [Fig. $3 A$, negative control (NC): $1.027 \pm 0.037$; TNXA-PS1 siRNA1: $0.455 \pm 0.153$, $\mathrm{p}=0.0223$ vs NC; TNXA-PS1 siRNA2: $0.393 \pm 0.056, p=0.0007$ vs NC; $n=3$ for each group, Student's $t$ test]. Transwell migration assays showed that silencing of lnc TNXA-PS1 expression in Schwann cells could promote their migration significantly compared with siRNA controls (Fig. $3 B$, NC: $1 \pm 0.082$; TNXA-PS1 siRNA1: $3.517 \pm 0.167, p<0.0001$ vs NC; TNXA-PS1 siRNA2: $2.628 \pm 0.275, p=0.0013$ vs NC; $n=4$ for each group, Student's $t$ test). In addition, TNXA-PS1 downregulation could also promote Schwann cell proliferation by approximately twofold. 
A

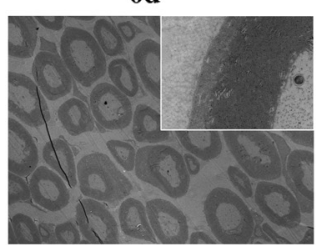

4d

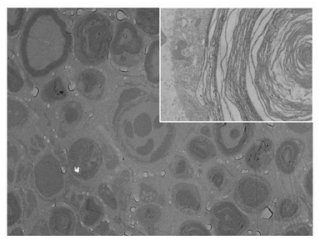

1d

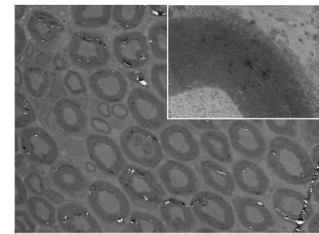

$7 d$

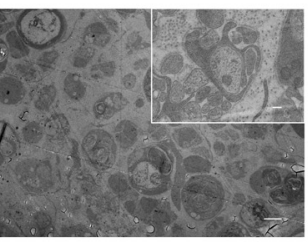

B

od

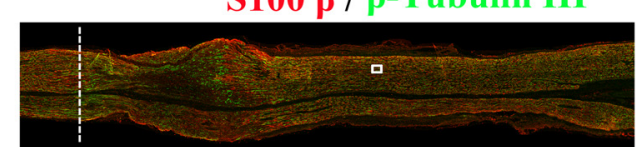

1d

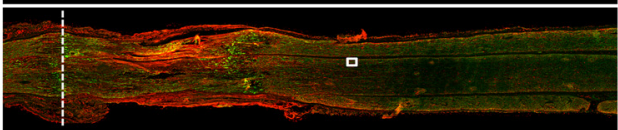

$4 d$

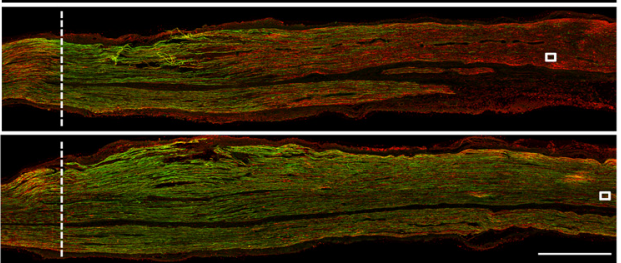

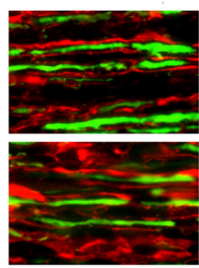

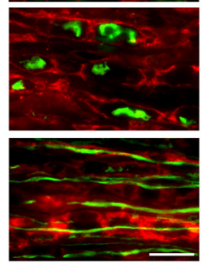

C

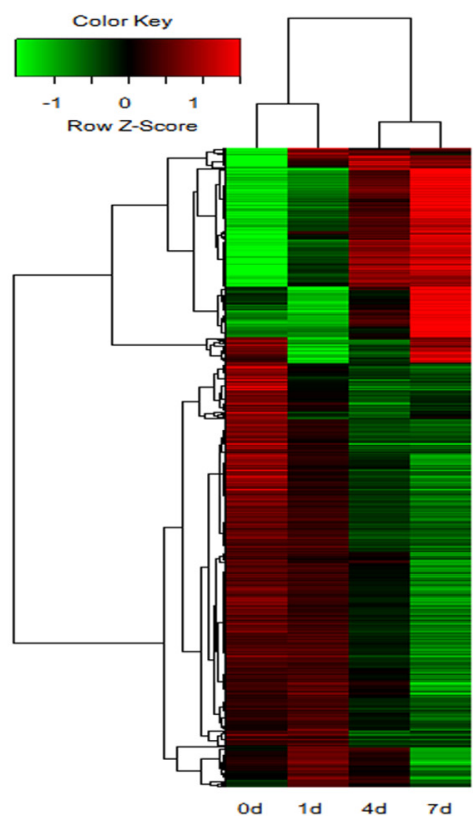

E

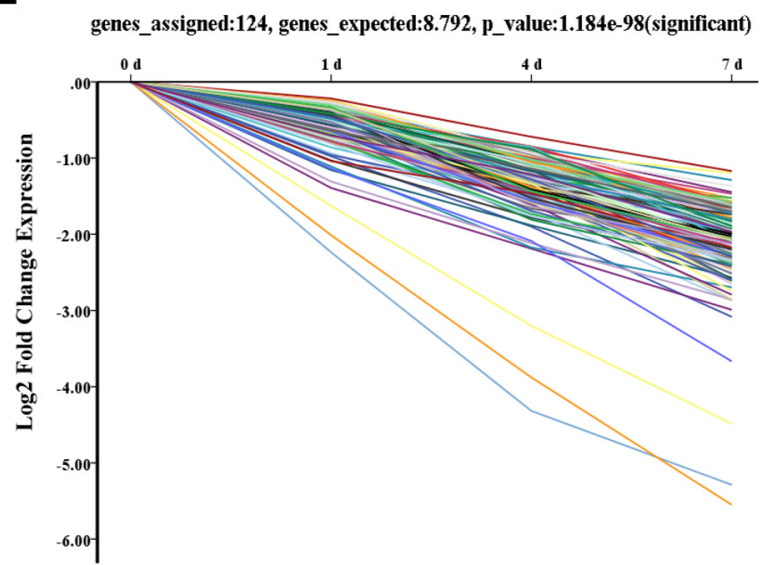

D
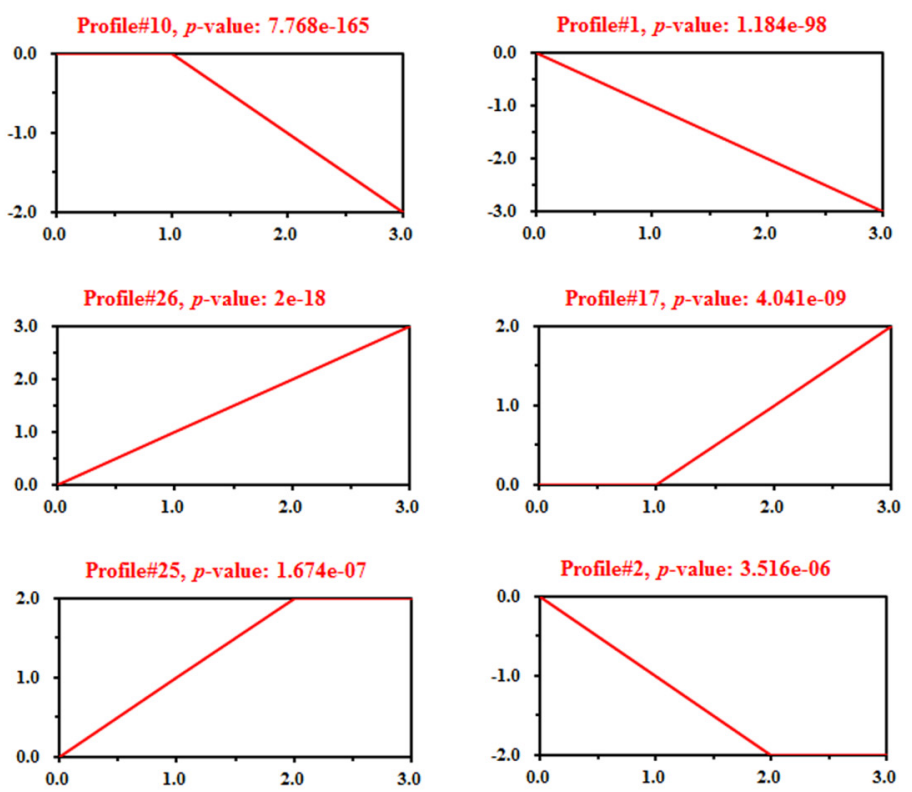

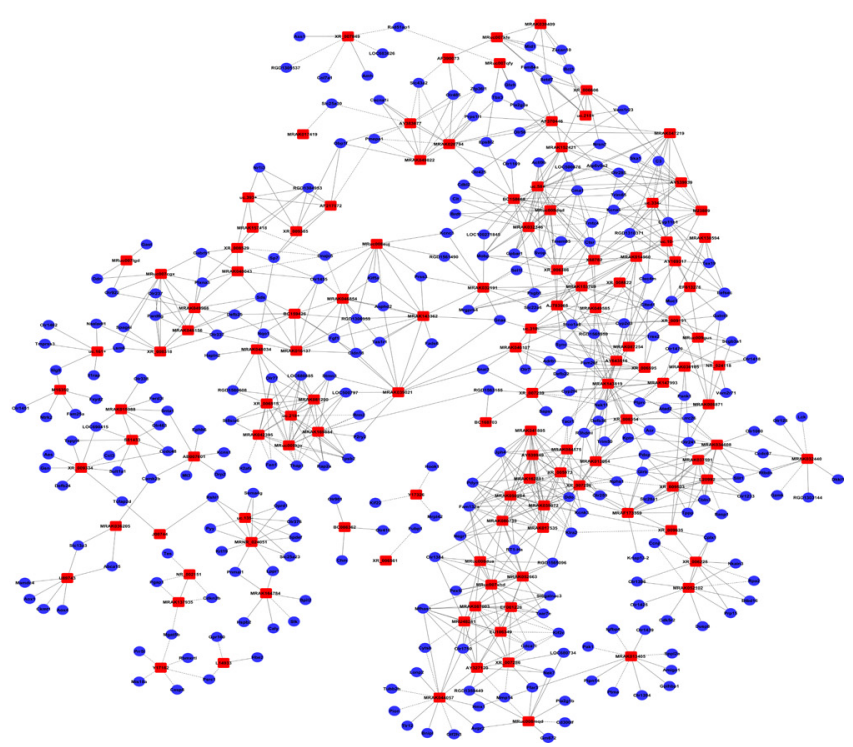

Figure 1. Dys-regulated IncRNAs following peripheral nerve injury. $A$, Electron microscopic analysis of cross-sections of sciatic nerves at $0,1,4$, and $7 \mathrm{~d}$ following sciatic nerve crush injury. Scale bar, $4 \mu \mathrm{m}$. Magnification images are shown in the right corner. Scale bar, $0.2 \mu \mathrm{m}$. B, Immunohistochemistry images of longitudinal sections of sciatic nerve at $0,1,4$, and $7 \mathrm{~d}$ following sciatic nerve crush injury. The white dotted line indicates the injury site. Schwann cells were stained with anti-S100 $\beta$ (green) and axons were stained with anti- $\beta$ Tubulin III (red). Scale bar, $1000 \mu \mathrm{m}$. Images on the right represent higher magnifications of the images on the left. Scale bar, $20 \mu \mathrm{m}$. C, Heatmap of 758 significantly differentially expressed IncRNAs at four (Figure legend continues.) 
Table 1. G0 analysis

\begin{tabular}{llrl}
\hline G0ID & G0 terms & Count & $p$-value \\
\hline G0:0007186 & G-protein-coupled receptor protein signaling pathway & 45 & 0.0001 \\
G0:0032501 & Multicellular organismal process & 102 & 0.0002 \\
G0:0051493 & Regulation of cytoskeleton organization & 10 & 0.0002 \\
G0:0031109 & Microtubule polymerization or depolymerization & 5 & 0.0004 \\
G0:0050877 & Neurological system process & 48 & 0.0008 \\
G0:0007606 & Sensory perception of chemical stimulus & 33 & 0.002 \\
G0:0046878 & Positive regulation of saliva secretion & 2 & 0.002 \\
G0:0050774 & Negative regulation of dendrite morphogenesis & 2 & 0.002 \\
G0:0044062 & Regulation of excretion & 3 & 0.002 \\
G0:0046777 & Protein autophosphorylation & 7 & 0.002 \\
\hline
\end{tabular}

We then wondered whether TNXA-PS1 could regulate Schwann cell migration in vivo. To investigate this, we injected Cy-5-labeled TNXA-PS1 siRNA and its negative control into the silicone-based nerve guidance conduit in a rat model of sciatic nerve injury. As detected by Sox10, a specific marker of Schwann cells, the distance of migrated Schwann cells was increased in the group of TNXA-PS1 siRNA injection (Fig. 3C,D, NC: $3212 \pm$ 115.2; TNXA-PS1 siRNA1: $6543 \pm 250.2, p=0.0003$ vs NC; TNXA-PS1 siRNA2: $5573 \pm 255.1, p=0.0011$ vs NC; $n=3$ for each group, Student's $t$ test). Moreover, immunostaining with anti- $\beta$-tubulin III showed that downregulation of TNXA-PS1 expression could also enhance axon regeneration, as estimated by the distance of axon outgrowth (Fig. $3 E, F, N C: 3156 \pm 60.59$; TNXA-PS1 siRNA1: $5156 \pm 561.7, p=0.024$ vs NC; TNXA-PS1 siRNA2: $4733 \pm 468.1, p=0.0288$ vs NC; $n=3$ for each group, Student's $t$ test). Therefore, these data suggested that TNXA-PS1 could also regulate Schwann cell migration in vivo, facilitating nerve regeneration.

\section{lnc TNXA-PS1 functions as an endogenous miRNA sponge in Schwann cells}

Next, we sought to explore the mechanisms behind the potent effect of lnc TNXA-PS1 on Schwann cell migration. Interactions with proteins have been recognized as a possible way that lncRNA to exerts its role (Moran et al., 2012). We then performed a RNA pull-down assay to identify proteins that are associated with lnc TNXA-PS1. However, we could not find any specific band between TNXA-PS1 and its antisense RNA (data not shown). Several recent reports also suggested that lncRNAs could function as ceRNA and affect the negative regulation of miRNAs on its target genes (Wang et al., 2013). Based on MRE enrichment (MuTaME) (Miranda et al., 2006; Tay et al., 2011), we identified 255 genes that could be the target gene regulated by TNXA-PS1 in the way of ceRNA. We then compared these genes with genes downregulated by TNXA-PS1 siRNAs as detected by microarray (1324 genes) and obtained 26 genes overlapped (Fig. 4A). Among them, nine genes (Ovol1, Ppargc1b, Plxna3, Bnipl, Aes, Dusp1, Sardh, Sfrp4 and Slit1) have been reported previously to be involved in cell migration and proliferation (Torigoe et al., 1996; Bellou et al., 2009; Fenster et al., 2010; Chen et al., 2011; Sun et al., 2014; Yuan

\footnotetext{
(Figure legend continued.) indicated time points after nerve injury. The color scale on the top illustrated the relative expression level of IncRNAs across all samples: red indicates expression $>0$ and green indicates expression $<0$. D, Six profiles of significant $p$-values according to expression pattern clustering. $\boldsymbol{E}$, Detailed expression changes of the 124 differentially expressed IncRNAs in sciatic nerve segment after nerve injury in Profile 1. $\boldsymbol{F}$, Coexpression network of IncRNAs in Profile 1 with correlated target genes. IncRNAs and coding mRNAs are presented as red squares and blue circles, respectively. The solid line between IncRNAs and coding mRNAs indicates positive correlation in expression; the dotted line indicates negative correlation.
}

et al., 2014; Duque-Afonso et al., 2015; Quek et al., 2015; FurióTarí et al., 2016; Liu et al., 2016; Wang et al., 2016). After qRTPCR validation, four genes (Plxna3, Slit1, Dusp1, and Ovol1) were downregulated by silencing TNXA-PS1 as the microarray analysis and were selected for further investigation (Fig. $4 B$, Plxna3: $0.317 \pm 0.041, p=0.0005$ vs NC; Slit1: $0.313 \pm 0.032$, $p=0.0002$ vs NC; Dusp1: $0.671 \pm 0.087, p=0.0321$ vs NC; Ovol1: $0.503 \pm 0.045, p=0.0016$ vs NC; $n=4$ for each group, Student's $t$ test). These genes were also downregulated following nerve injury, especially at day 1 (Fig. $4 C$, Plxna3: $1 \mathrm{~d}$ : $0.172 \pm$ $0.003, p=0.0002$ vs $0 \mathrm{~d} ; 4 \mathrm{~d}: 0.318 \pm 0.010, p=0.0004$ vs $0 \mathrm{~d} ; 7 \mathrm{~d}$ : $0.751 \pm 0.064, p=0.061$ vs $0 \mathrm{~d}$; Slit1: $1 \mathrm{~d}: 0.273 \pm 0.011$, $p=0.0183$ vs $0 \mathrm{~d} ; 4 \mathrm{~d}$ : $0.544 \pm 0.011, p=0.0447$ vs $0 \mathrm{~d} ; 7 \mathrm{~d}$ : $0.544 \pm 0.033, p=0.0486$ vs $0 \mathrm{~d}$; Dusp1: $1 \mathrm{~d}: 0.394 \pm 0.008$, $p=0.0045$ vs $0 \mathrm{~d} ; 4 \mathrm{~d}: 0.415 \pm 0.018, p=0.0056$ vs $0 \mathrm{~d} ; 7 \mathrm{~d}$ : $0.523 \pm 0.008, p=0.0073$ vs $0 \mathrm{~d}$; Ovoll: $1 \mathrm{~d}: 0.306 \pm 0.002, p=$ 0.0029 vs $0 \mathrm{~d} ; 4 \mathrm{~d}: 0.406 \pm 0.015, p=0.0046$ vs $0 \mathrm{~d} ; 7 \mathrm{~d}: 1.046 \pm$ $0.013, p=0.3646$ vs $0 \mathrm{~d}$ ).

We then sought to validate the relationship among TNXAPS1, miRNAs, and target genes. As shown in Figure $4 A$, there were 11 miRNAs shared by TNXA-PS1 and the selected four genes. We constructed a luciferase plasmid of TNXA-PS1 (pmirGLO-TNXA-PS1). Luciferase assay showed that miR-243p, miR-320-3p, miR-485-5p, miR-152-3p, and miR-330-5p could reduce the luciferase activity of TNXA-PS1 significantly, suggesting that TNXA-PS1 may interact with these five miRNAs (Fig. 4D, miR-24-3p: $0.847 \pm 0.014, p=0.0084$ vs MC; miR-3203p: $0.702 \pm 0.047, p=0.0245$ vs MC; miR-485-5p: $0.748 \pm 0.011$, $p=0.0019$ vs MC; miR-152-3p: $0.861 \pm 0.017, p=0.0148$ vs MC; miR-330-5p: $0.597 \pm 0.034, p=0.007$ vs MC; $n=3$ for each group, Student's $t$ test). The 3 '-UTR of the predicted target gene of these miRNAs, Plxna3, Dusp1, and Slit1, were also constructed into luciferase vector and luciferase assay indicated that the $3^{\prime}$ UTR of Plxna3 and Dusp1 could bind with miR-24-3p/320-3p/ 485-5p and miR-24-3p/152-3p, respectively (Fig. 4E, Plxna3 group: miR-24-3p: $0.668 \pm 0.018, p=0.0029$ vs MC; miR-3203p: $0.823 \pm 0.029, p=0.0251$ vs MC; miR-485-5p: $0.464 \pm 0.031$, $p=0.0034$ vs MC; Dusp1 group: miR-24-3p: $0.836 \pm 0.026, p=$ 0.0246 vs MC; miR-152-3p: $0.578 \pm 0.026, p=0.0039$ vs MC; miR-330-5p: $1.086 \pm 0.067, p=0.3247$ vs MC; $n=3$ for each group, Student's $t$ test). Dusp1 was selected for further validation. It was shown that miR-24-3p and miR-152-3p could decrease both mRNA and protein expression level of Dusp1 in Schwann cells (Fig. 4F, G, Dusp1 mRNA: miR-24-3p: 0.499 $\pm 0.037, p=$ 0.0054 vs MC; miR-152-3p: $0.303 \pm 0.039, p=0.0031$ vs MC; Dusp1 protein: $\operatorname{miR}-24-3 p: 0.346 \pm 0.079, p=0.0142$ vs MC; miR-152-3p: $0.273 \pm 0.095, p=0.0168$ vs MC; $n=3$ for each group, Student's $t$ test).

\section{Dusp1 inhibited Schwann cell migration}

We suspected that TNXA-PS1 might regulate Schwann cell migration through Dusp1 by sponging certain miRNAs, so we further detected the effect of Dusp1 on Schwann cell migration. The mRNA and protein expression of Dusp1 were both downregulated significantly by Dusp 1 siRNAs (Fig. $5 A$, NC: $0.037 \pm 0.003$; Dusp1 siRNA1: $0.017 \pm 0.004, p=0.0105$ vs NC; Dusp1 siRNA2: $0.012 \pm 0.001, p=0.0004$ vs NC; $n=4$ for each group, Student's $t$ test). Transwell migration assay showed that interfering Dusp1 expression by siRNAs could promote Schwann cell migration (Fig. 5B; Dusp1 siRNA1: $1.634 \pm 0.208, p=0.056$ vs NC; Dusp 1 siRNA2: $2.013 \pm 0.169, p=0.0078$ vs NC; $n=3$ for each group, Student's $t$ test). We also constructed plasmid of Dusp1 (pcDNA3.1-Dusp1) and transfected it into Schwann cells. 
A

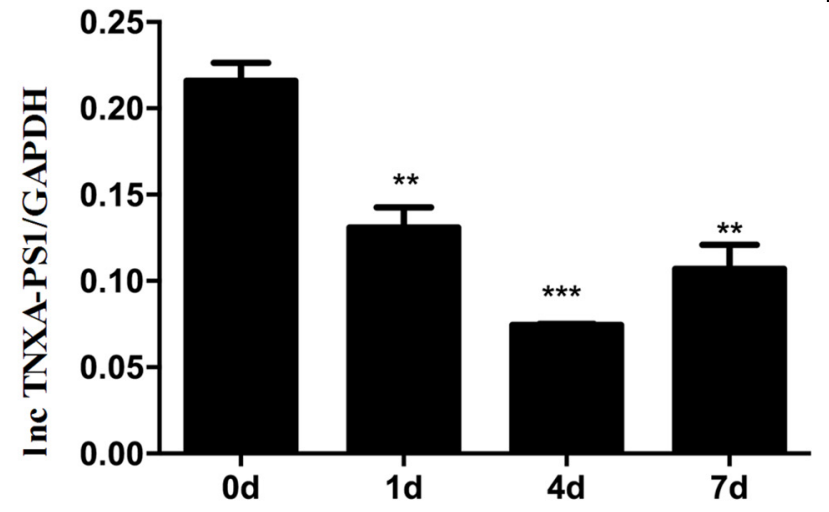

B $0 \mathrm{~d}$
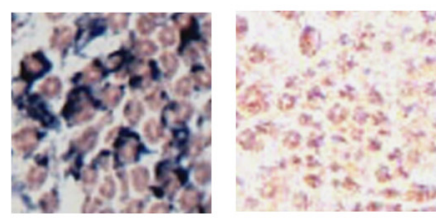

$4 \mathrm{~d}$

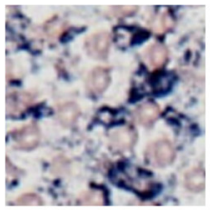

TNXA-PS1

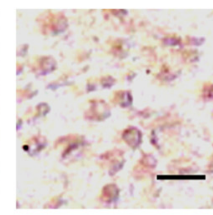

Control

C

IncRNA TNXA-PS1- full- length: $1548 \mathrm{nt}$

1 CIAGCAGATG GAGGAGAGCC ACAAAGIGIG CAGGigGATG GCCGGACCCA CACCCAGATC CICCAGGGG ICAITCCGGA CACTCGCIAT GAGGTGACIG

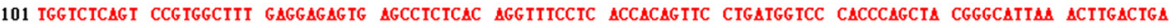
201 CAGATCTGCC CITCTGCACT GGAAACCTCC CCACAAGCCG GIGGACAAAT ACAACGTCCA GGICGCATCC CCIGGGGCC CACCCCIICA GGCCTCGGCA 301 CCTGGCAGCG CTGTGGACTA CCCGCTGACG GACCTGTCAC TGGACACCAA ITACACAGCC ACCGTGCGTG GTCTCCGGGG TCCTAACITC ACCTCCCCAG 401 CCAGCATIAA CITCACCACA GGGITAAAGC CCCCCCAGGA CITGGAGGCC AAGGAAGTGA CTCCTCGAAC GGCCCTGCTC ACTIGGACCG CGCCTABGGI 501 TCCACCCACA GGCTACCTGC ICAGCITIGA CACCCCCGGA GGACAGATIC AGGAAATCCT GCTTCCAGCA GGGACCACCT CACACAGGCI TCTCCGCCTC 601 ITCCCCTCCA CCITCIACAG CGCCCAGCTC CGGGCIAIII GGGGCGAGAG CCTCACACCT CCTGIGTCCA CIICCIITAC IACTGGIGGG CTGCGGATCC 701 CCTTCCCCAG GGACTGTGGG GAGGAGCTGA $\triangle A A A T G G G G C$ CAGCGCCTCA $\triangle A G A C C A C C A$ CCATCTTCCT CAATGGCAAC CGCGAGCGGC CCTTGGATGI 801 GITTTGTGAC ATGCAGACTG ACGGAGGAGG ITGGCIGGIG ITCCAGCGCC GCATGGACGG ACAGACAGAC IICTGGAGAG ACTGGGAGGA GIACGCCCAT 901 GGITTCGGGA ACATCTCCAG GGAATICTGG CTGGGCAATG AGGCCCITCA CAGCCTCACG CAGGCTGGAG ACTACTCTAT GCGTGTGGAC CTGCGGGCCG 1001 GAAAGGASGC CGTGITCGCC CAGIAIGACT TCIICCGAGT AGACTCAGCG $\triangle A G G A G \Delta A C T$ ATCGTCTACA CCIAGGGGGC IACCATGGGA CCGCGGGTGA 1101 CTCTATGAGC IACCACAGCG GCAGIGICIT IICGGCCCGI GATCGAGACC CCAATAACTT GCTCATCTCC IGCGCIGTCI CCIACCG IGG CGCTIGG IGG 1201 TACAAGAACT GICACIACGC CAACCICAAC GGGCICIAIG GAAGCACAGI GGATCACCAG GGAGTGAGCT GGIACCACTG GAAGGGCIIC GAGITCICGG 1301 IGCCCTICAC GGAAATGAAG CIGAGACCCA GAAACIICCA GGCCCCCACC AGGGGCACCT GAGCCTGCTG CCCACCTCAC ICACACCCIG GIATGACTGC 1401 CGAGCACTGA GGGGITGTGC CCAGAGAAGA GCCAGTGIGI CTCIACTGIG CCTAGCTCAC CGAGGAAGCC IICICIGCCA CAGICICACA GCACCATGIT 1501 TACAGGGGGG AGGGGAGGGG AATGGAGCAA TAAAGGAGAS ACTGAGGCAA

D

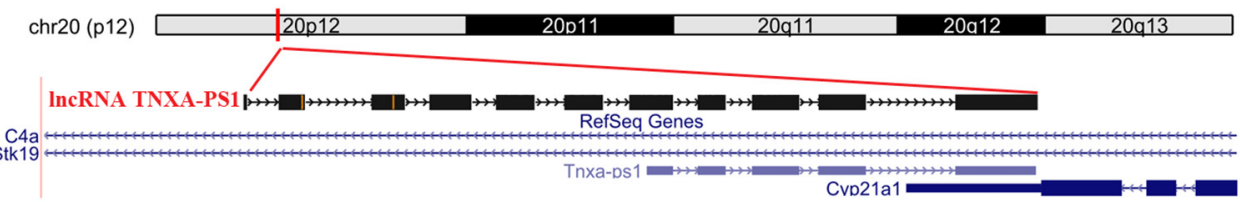

E

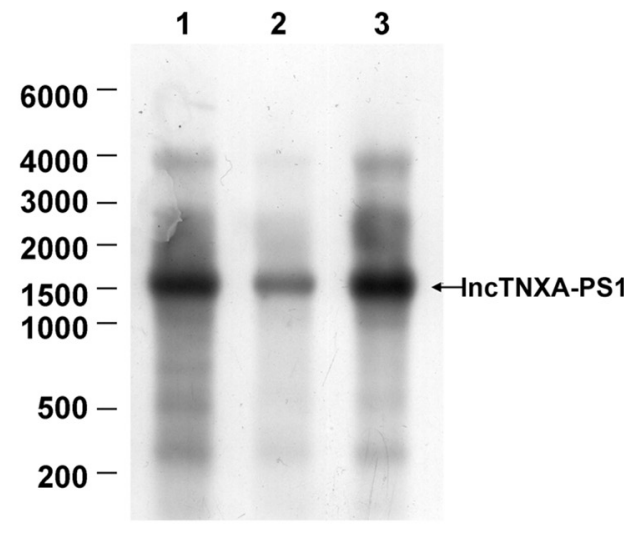

$\mathbf{F}$

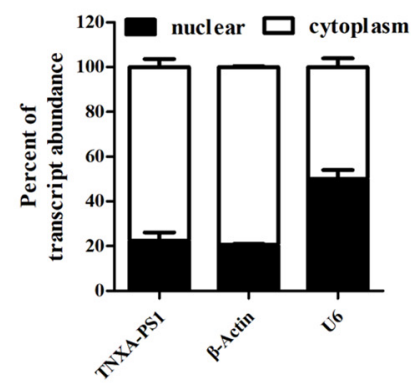

G
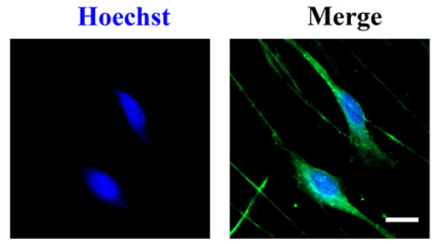

Figure 2. Expression and localization of Inc TNXA-PS1.A, Validation of TNXA-PS1 expression in sciatic nerve segments after nerve injury as shown by qRT-PCR. $B$, In situ hybridization of TNXA-PS1 on sciatic nerve tissue sections at 0 and $4 \mathrm{~d}$ after nerve injury. Scale bar, $10 \mu \mathrm{m}$. C, Full sequence of TNXA-PS1 as detected by RACE. The nucleotide sequence of the full-length TNXA-PS1 identified by RACE is indicated in red. The reference sequence of TNXA-PS1 (NR_024118) is from the NCBI database. D, Scheme of TNXA-PS1 in rat genome searched by UCSC Genome Browser. The red line in the chromosome indicates the localization of IncRNA TNXA-PS1 in genome. Under the chromosome is the composition of TNXA-PS1. The black blocks indicate exons and the line between blocks represents introns. The arrows in line suggested the direction of transcription. RefSeq genes around IncRNAs TNXA-PS1 are also illustrated. $\boldsymbol{E}$, Northern blot analysis of TNXA-PS1 in sciatic nerve tissue. Lines 1-3 represent sciatic nerve tissue RNA samples of three rats. $F$, Fractionation of Schwann cell lysates demonstrating cytoplasm expression of TNXA-PS1. $\beta$-Actin served as a positive control for cytoplasm gene expression; U6 served as a positive control for nuclear gene expression ( $n=4$ for each group). $\mathbf{G}$, Subcellular localization analysis of Inc TNXA-PS1 by RNA FISH demonstrating localization of TNXA-PS1 in the cytoplasm. Scale bar, $10 \mu \mathrm{m}$. Values are mean \pm SEM. Statistical significance was assessed by two-tailed Student's $t$ test, ${ }^{* *} p<0.01$, ${ }^{* * *} p<0.001$. 
A

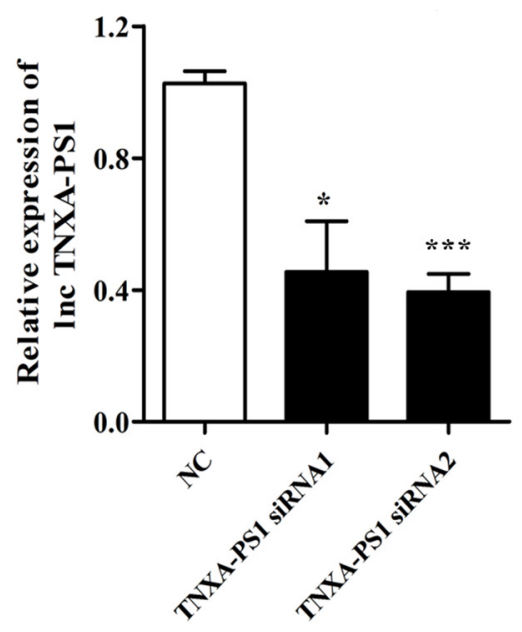

B

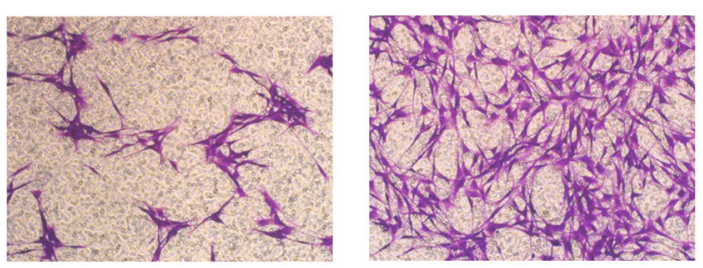

TNXA-PS1 siRNA1

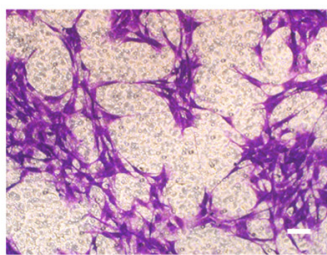

TNXA-PS1 siRNA2

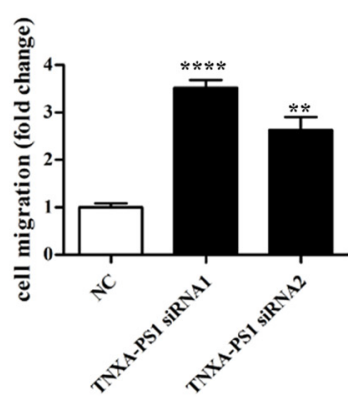

C

Sox10/Hoechst
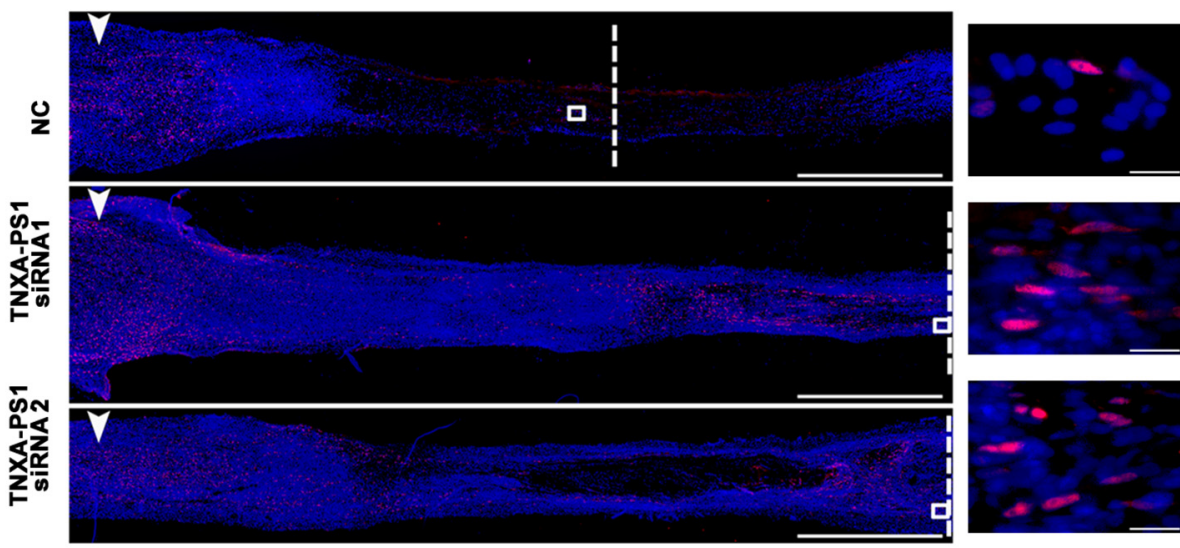

D
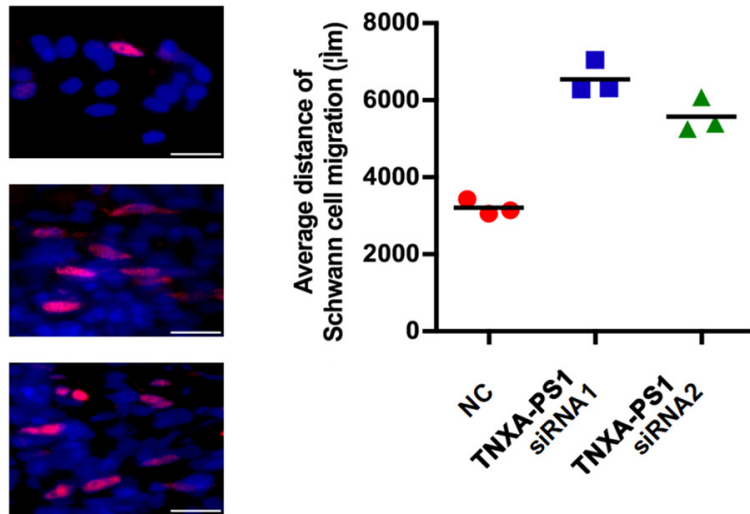

E
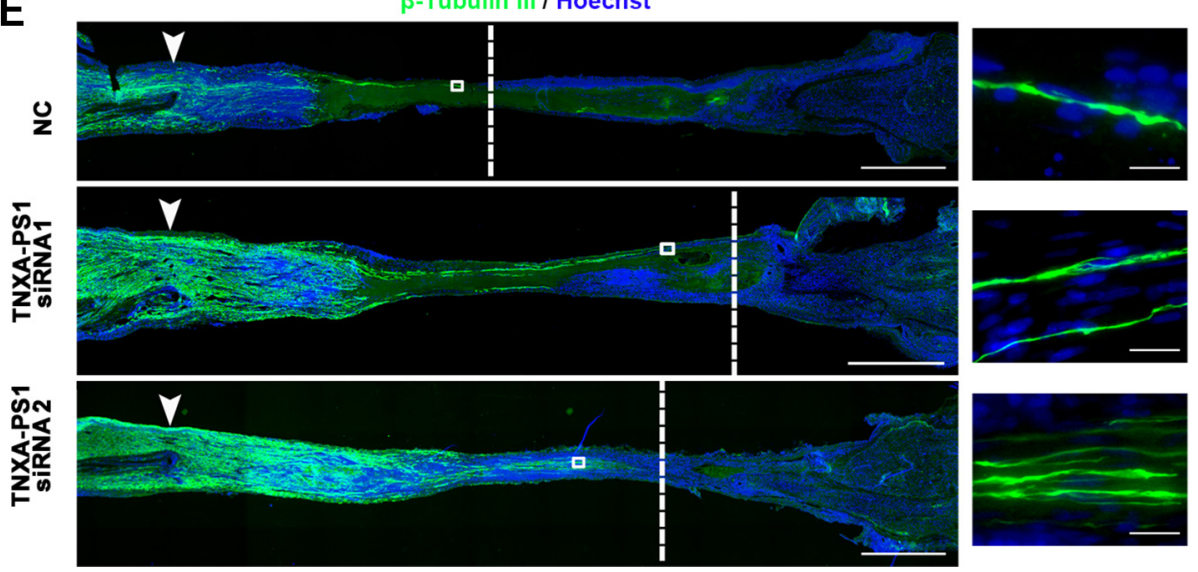

F

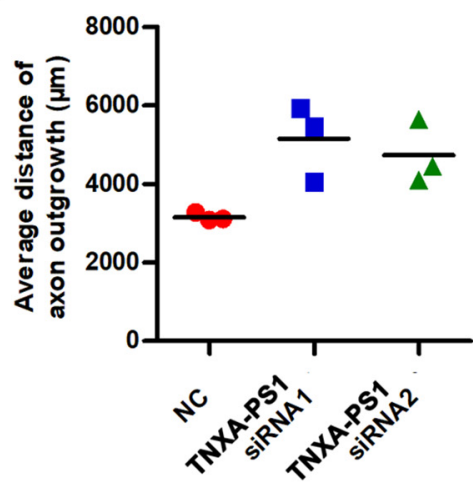

Figure 3. TNXA-PS1 affects Schwann cell migration. $A$, TNXA-PS1-specific siRNAs decreased TNXA-PS1 expression in Schwann cells as detected by qRT-PCR ( $n=3$ for each group). $\boldsymbol{B}$, Both siRNA-1 and siRNA-2 of TNXA-PS1 promoted Schwann cell migration significantly compared with siRNA control. Representative images and quantification data of Transwell migration assay are shown. Scale bar, $50 \mu \mathrm{m}$ ( $n=4$ for each group). C, Schwann cell migration in silicon conduits injected with TNXA-PS1 siRNA was faster compared with negative control (NC) as detected by immunostaining. Red: Sox10 positive Schwann cells; blue: cell nucleus. The white arrow indicates the edge of the proximal stump and the distance of Schwann cells migration from the edge of the proximal stump (white dotted line) were counted. Scale bar, $1000 \mu \mathrm{m}$. Images in the right represented the higher magnifications of the white square in the left images. Scale bar, $20 \mu \mathrm{m}$. D, Statistical comparison for the average distance of migrating Schwann cells in silicon conduits, $n=3$ for each group. $\boldsymbol{E}$, Axon outgrowth in the regenerative conduit injected with TNXA-PS1 siRNA or with NC. The proximal stump of the transection site is indicated by white arrows and the end of axon outgrowth is labeled with white dotted line. Axons were immunostaining by $\beta$-Tubulin III in green. Scale bar, $1000 \mu \mathrm{m}$. Images on the right represent higher magnifications of the white square in the left images. Scale bar, $20 \mu \mathrm{m}$. $F$, Average distance of axon outgrowth in silicon conduits ( $n=3$ for each group). Values are mean \pm SEM. Statistical significance was assessed by two-tailed Student's $t$ test, ${ }^{*} p<0.05,{ }^{* *} p<0.01,{ }^{* * *} p<0.001,{ }^{* * * *} p<0.0001$. 
A

Inc TNXA-PS1 siRNA Target genes of lne TNXA-PS1 down-regulation genes

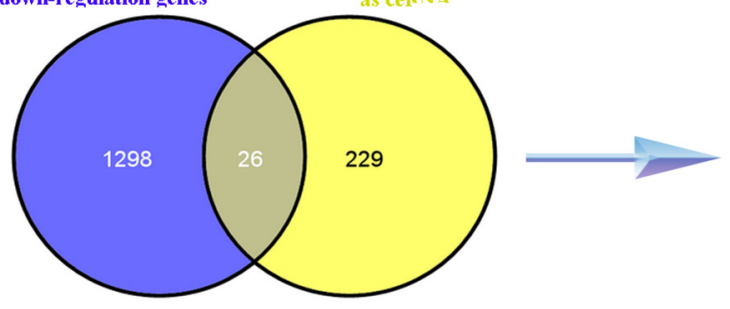

B

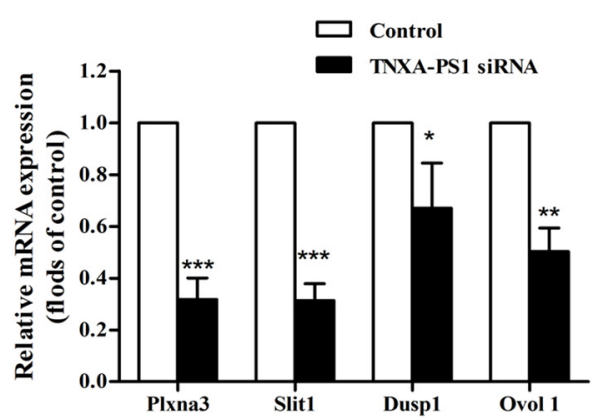

D

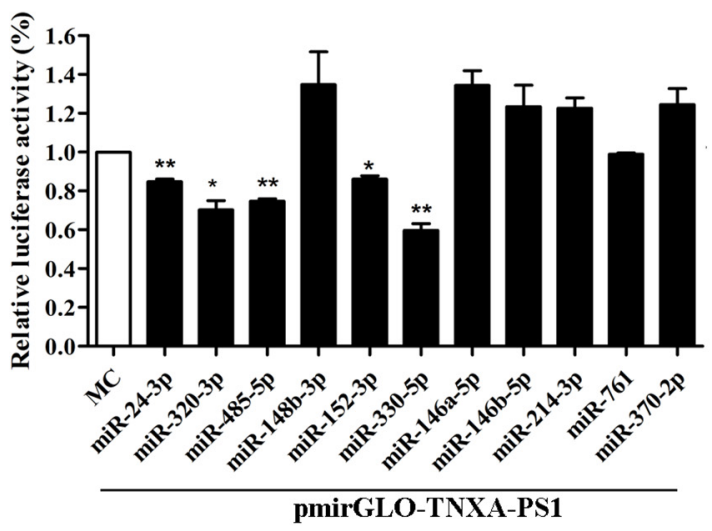

$\mathbf{F}$

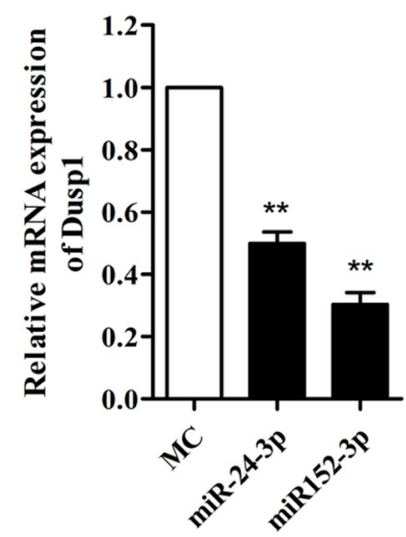

G
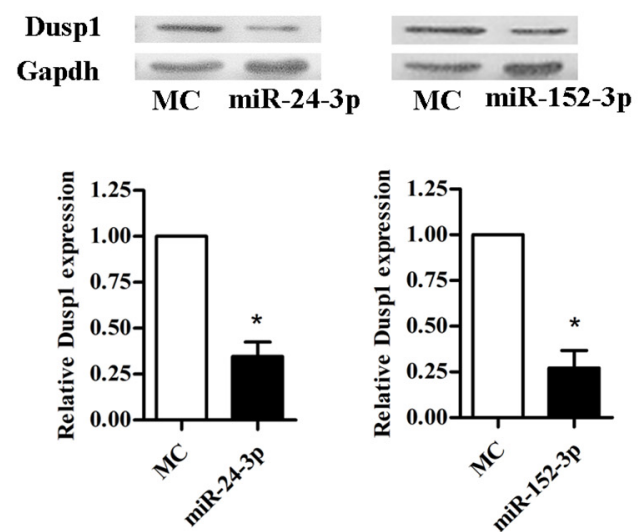

Figure 4. TNXA-PS1 might regulate Dusp1 expression by binding with miR-24-3p and miR-152-3p. A, Coverage of the downregulated genes by TNXA-PS1 siRNA and target genes of TNXA-PS1 as ceRNA. Four possible target genes were selected and the binding sites of miRNAs with TNXA-PS1 and target genes are illustrated on the right. $\boldsymbol{B}$, Validation of the downregulation of target genes of TNXA-PS1 by TNXA-PS1 siRNA in Schwann cells ( $n=4$ for each group). C, Validation of target gene expression in sciatic nerve segment following nerve injury ( $n=4$ for each group). $\boldsymbol{D}$, Luciferase analysis of the interaction between TNXA-PS1 and the related 11 miRNAs ( $n=3$ for each group). $\boldsymbol{E}$, Luciferase analysis of the interaction between target genes and the related miRNAs ( $n=3$ for each group). $\boldsymbol{F}, \mathrm{mRNA}$ expression of Dusp1 was downregulated by miR-24-3p and miR-152-3p, $n=3$ for each group. G, Protein expression level of Dusp1 was downregulated by miR-24-3p and miR-152-3p. Top, Western blot of Dusp1. Bottom, Quantification of Western blot results ( $n=3$ for each group). Values are mean \pm SEM. Statistical significance was assessed by two-tailed Student's $t$ test, ${ }^{*} p<0.05,{ }^{* *} p<0.01,{ }^{* * *} p<0.001$. 
A

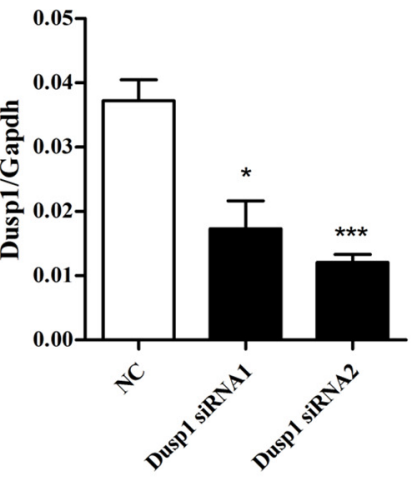

B

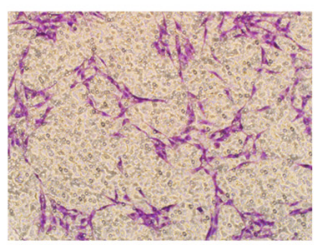

NC

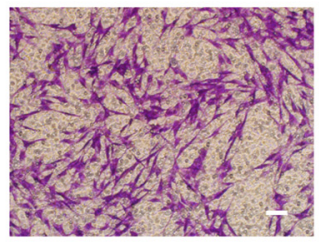

Dusp1 siRNA2

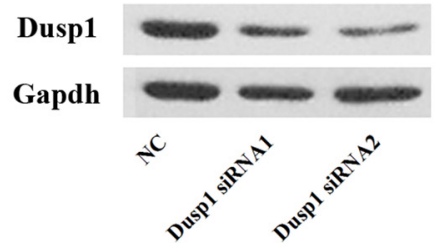

C
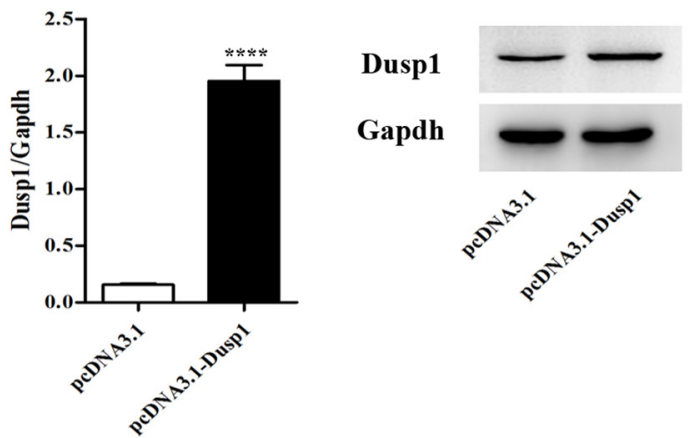

D

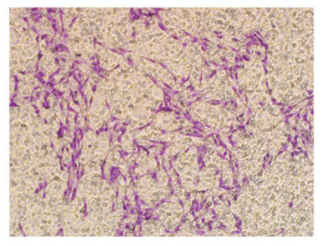

Dusp1 siRNA1

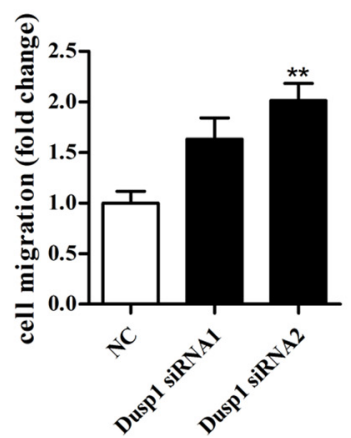

E
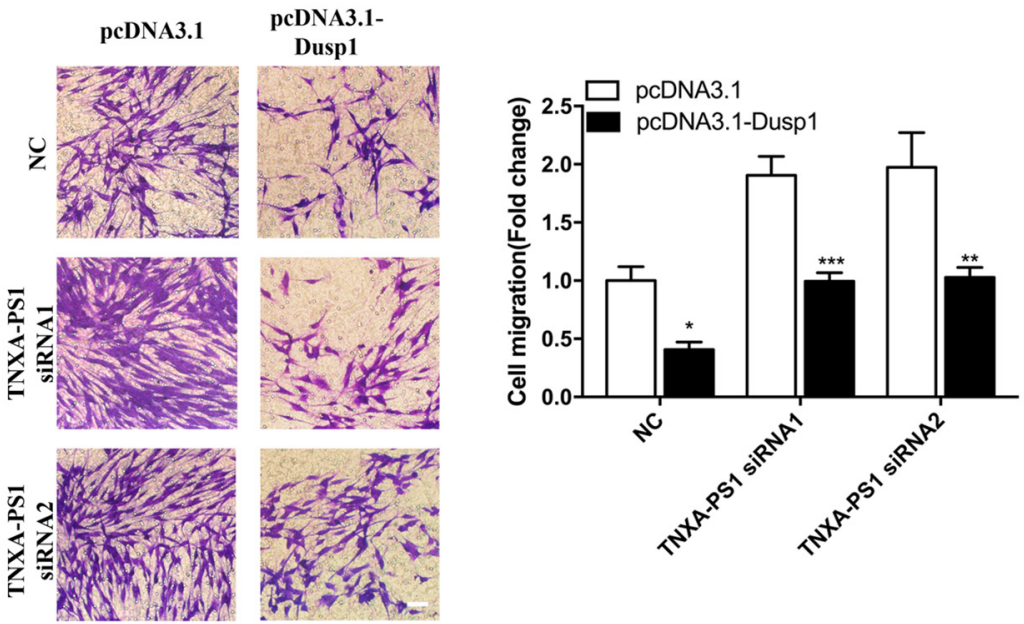

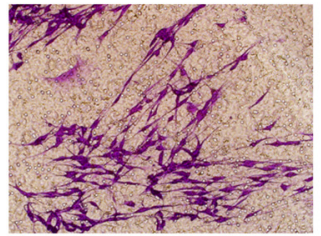

pcDNA3.1

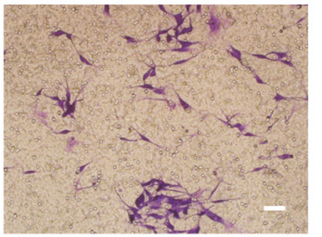

pcDNA3.1-Dusp1

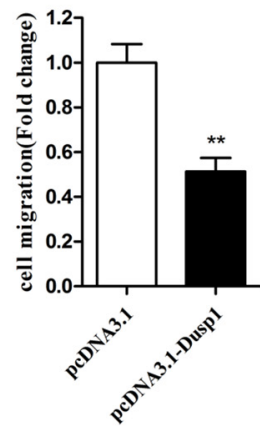

$\mathbf{F}$

peripheral nerve injury

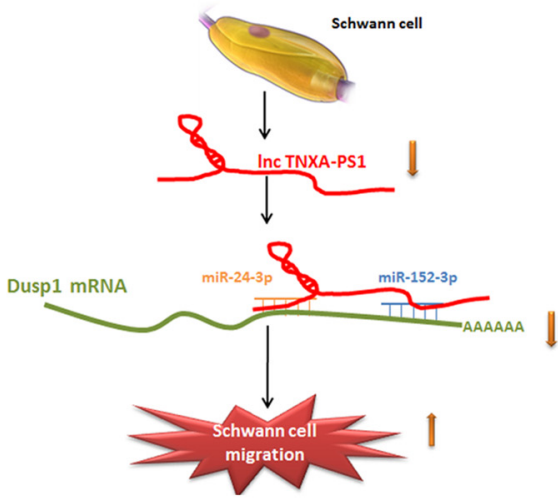

Figure 5. TNXA-PS1 regulate Schwann cell migration by Dusp1. $A$, Interfering efficiency of siRNAs on Dusp 1 in Schwann cells as detected by qRT-PCR (left) and Western blot (right) ( $n=4$ for each group). B, Silencing Dusp1 promotes Schwann cell migration compared with siRNA control. Representative images and quantification data of transwell migration assay are shown ( $n=3$ for each group). Scale bar, $50 \mu \mathrm{m}$. C, mRNA (left) and protein (right) expressions of Dusp1 were elevated by overexpression plasmid pcDNA3.1-Dusp1 ( $n=5$ for each group). $\boldsymbol{D}, 0$ verexpressing Dusp1 inhibited Schwann cell migration as detected by Transwell migration assay ( $n=3$ for each group). $\boldsymbol{E}$, Overexpression of Dusp1 could antagonize the promotion effect of TNXA-PS1 siRNA on Schwann cell migration $(n=3-8)$. Scale bar, $50 \mu \mathrm{m}$. $\boldsymbol{F}$, Schematic representation of the regulation of TNXA-PS1 suggesting that, after sciatic nerve injury, TNXA-PS1 was downregulated and there was less binding with miR-24-3p and miR-152-3p. These miRNAs then interacted with Dusp1 and reduced Dusp1 expression, encouraging Schwann cell migration. Values are shown as mean \pm SEM. Statistical significance was assessed by two-tailed Student's t test, ${ }^{*} p<0.05,{ }^{* *} p<0.01,{ }^{* * *} p<0.001$.

qRT-PCR and Western blot results showed that the mRNA and protein expression of Dusp1 were increased dramatically (Fig. 5C; pcDNA3.1: $0.157 \pm 0.010 ;$ pcDNA3.1-Dusp1: $1.954 \pm 0.139$, $p<0.0001$ vs pcDNA3.1; $n=5$ for each group, Student's $t$ test).
Transwell migration assay indicated that Schwann cell migration was decreased by Dusp1 overexpression (Fig. 5D; pcDNA3.1Dusp1: $0.5135 \pm 0.060, p=0.0089$ vs pcDNA3. $1 ; n=3$ for each group, Student's $t$ test). Additionally, overexpression of Dusp1 
on Schwann cells, which silenced lnc TNXA-PS1, could antagonize the promotion effect of lnc TNXA-PS1 siRNAs on Schwann cell migration (Fig. 5E, siRNA NC+pcDNA3.1: $1 \pm 0.1192$, siRNA NC+pcDNA3.1-Dusp1: $0.4065 \pm 0.06548, p=0.012$; TNXA-PS1 siRNA1+pcDNA3.1: $1.906 \pm 0.1611$, TNXA-PS1 siRNA1+pcDNA3.1-Dusp1: $0.9944 \pm 0.07413, p=0.0001$; TNXA-PS1 siRNA2+pcDNA3.1: $1.974 \pm 0.2974$, TNXA-PS1 siRNA2+pcDNA3.1-Dusp 1: $1.029 \pm 0.08391, p=0.0018 ; n=$ $3-8$, Student's $t$ test). These data suggested that lnc TNXA-PS1 might regulate Schwann cell migration by Dusp1.

\section{Discussion}

One major characteristic of the PNS is its ability to spontaneously regeneration following nerve injury. As we know, because of its growth-inhibitory environment, CNS lacks intrinsic growth capacity. However, there is a more permissive growth environment in the PNS due to an efficient and extensive removal of myelin debris and inhibitors by Schwann cells and macrophages (Christie and Zochodne, 2013). The dedifferentiation, proliferation, migration, and myelin clearance of Schwann cells, a vast majority of cells in the injured distal nerve stump, are evidently associated with successful nerve regeneration (Bosse, 2012). Research has shown that blocking Schwann cell proliferation and migration might attenuate axonal regeneration in transected nerves (Chen et al., 2005). Therefore, clarifying the mechanisms underlying the modulation of Schwann cell behavior and finding promising molecules for nerve injury therapy are of great importance. In addition to growth factors and extracellular matrix substrates (Akassoglou et al., 2003; Perlin et al., 2011; Wakatsuki et al., 2014), our group and others have shown that miRNAs are also involved in Schwann cell phenotype modulation (Verrier et al., 2010; Yu, Qian et al., 2012; Yu, Zhou et al., 2012; Zhou et al., 2014). Here, we have shown for the first time that lncRNA TNXA-PS1 can regulate Schwann cell migration as an miRNA sponge.

Because of recent technological advances, thousands of lncRNAs have been demonstrated to be transcribed pervasively in the genome (Moran et al., 2012). Although lncRNAs have no significant protein-coding capacity, they are involved in diversity cellular biological processes and diseases, highlighting a central role in cell homeostasis (Wu et al., 2013). In the CNS, lncRNAs have been shown to participate in brain development, neural differentiation and maintenance, synaptic plasticity, and so on (Wu et al., 2013). However, studies on the role of lncRNAs in the PNS are rare. lncRNA, a Kcna2 antisense RNA, could contribute to neuropathic pain by silencing Kcna 2 in primary afferent neurons. In addition, we have previously detected altered lncRNA expression in DRG after rat sciatic nerve injury and confirmed that lncRNA uc.217 could affect neurite outgrowth (Yu et al., 2013; Yao et al., 2015). Recently, Xu et al. (2017) has identified differentially expressed lncRNAs between IL-22 and control groups on Schwann cells in vitro. Here, we investigated lncRNA alteration in sciatic nerve segment following peripheral nerve injury and identified lncRNA TNXA-PS1 as a negative regulator for Schwann cell migration.

lncRNAs could exert their function by interacting with DNA, RNA, and protein. According to recent reports, lncRNAs might function as ceRNAs, sponging and affecting the target genes of miRNAs (Cesana et al., 2011; Kallen et al., 2013). Considering the mainly cytoplasmic distribution of TNXA-PS1 in Schwann cells, as identified by qRT-PCR, we speculated that TNXA-PS1 might also exert its regulatory role by sponging miRNAs. Therefore, in our study, we conducted bioinformatic prediction and found several possible miRNAs and target genes that could be regulated by TNXA-PS1 in the mechanism of ceRNA. Following luciferase assay validation, we confirmed that TNXA-PS1 could bind with miR24-3p and miR-152-3p, both of which have the same target gene, Dusp1.

miR-24-3p and miR-152-3p are both involved in tumorigenesis and cell migration. miR-24-3p could regulate the proliferation and migration of human arterial smooth muscle cells by targeting platelet-derived growth factor receptor B and c-Myc, whereas forced miR-152 expression reduced the migratory and invasive capabilities of prostate cancer cells significantly in vitro (Zhu et al., 2013, 2015). Dusp1 is recognized as an inactivator of different MAPK isoforms and is involved in multiple cell biological behaviors (Abraham et al., 2006; Shen et al., 2016). Dusp1 suppression induced by IL-17 could activate p38 MAPK and ERK1/2, promoting mouse primary cardiac fibroblast proliferation and migration (Valente et al., 2012). In our study, overexpression or interference of Dusp 1 affected Schwann cell migration significantly. We thus speculated that, TNXA-PS1 might weaken miR-24-3p/miR125-3p-mediated Dusp1 suppression by sponging miR-24-3p/ miR-125-3p. Following nerve injury, the expression of Dusp1 was decreased as a result of TNXA-PS1 downregulation, eventually promoting Schwann cell migration (Fig. $5 F$ ).

In conclusion, our study has shown for the first time global lncRNA in a sciatic nerve segment following peripheral nerve injury in rats. We further characterized and functionally evaluated one continuously downregulated lncRNA, TNXA-PS1. Our research showed that TNXA-PS1 might regulate Schwann cells migration by sponging $\mathrm{miR}-24-3 \mathrm{p} / \mathrm{miR}-152-3 \mathrm{p}$ and affecting Dusp1 expression. Together, these findings suggested that lncRNAs play a regulatory role in Schwann cell behavior and might be a potential therapeutic target for peripheral nerve injury.

\section{References}

Abraham SM, Lawrence T, Kleiman A, Warden P, Medghalchi M, Tuckermann J, Saklatvala J, Clark AR (2006) Antiinflammatory effects of dexamethasone are partly dependent on induction of dual specificity phosphatase 1. J Exp Med 203:1883-1889. CrossRef Medline

Akassoglou K, Akpinar P, Murray S, Strickland S (2003) Fibrin is a regulator of Schwann cell migration after sciatic nerve injury in mice. Neurosci Lett 338:185-188. CrossRef Medline

Bellou S, Hink MA, Bagli E, Panopoulou E, Bastiaens PI, Murphy C, Fotsis T (2009) VEGF autoregulates its proliferative and migratory ERK1/2 and p38 cascades by enhancing the expression of DUSP1 and DUSP5 phosphatases in endothelial cells. Am J Physiol Cell Physiol 297:C1477-C1489. CrossRef Medline

Bosse F (2012) Extrinsic cellular and molecular mediators of peripheral axonal regeneration. Cell Tissue Res 349:5-14. CrossRef Medline

Cesana M, Cacchiarelli D, Legnini I, Santini T, Sthandier O, Chinappi M, Tramontano A, Bozzoni I (2011) A long noncoding RNA controls muscle differentiation by functioning as a competing endogenous RNA. Cell 147:358-369. CrossRef Medline

Chen LL, Carmichael GG (2010) Long noncoding RNAs in mammalian cells: what, where, and why? Wiley Interdiscip Rev RNA 1:2-21. CrossRef Medline

Chen X, Overcash R, Green T, Hoffman D, Asch AS, Ruiz-Echevarría MJ (2011) The tumor suppressor activity of the transmembrane protein with epidermal growth factor and two follistatin motifs 2 (TMEFF2) correlates with its ability to modulate sarcosine levels. J Biol Chem 286: 16091-16100. CrossRef Medline 
Chen YY, McDonald D, Cheng C, Magnowski B, Durand J, Zochodne DW (2005) Axon and Schwann cell partnership during nerve regrowth. J Neuropathol Exp Neurol 64:613-622. CrossRef Medline

Cheng XL, Wang P, Sun B, Liu SB, Gao YF, He XZ, Yu CY (2015) The longitudinal epineural incision and complete nerve transection method for modeling sciatic nerve injury. Neural Regen Res 10:1663-1668. CrossRef Medline

Christie KJ, Zochodne D (2013) Peripheral axon regrowth: new molecular approaches. Neuroscience 240:310-324. CrossRef Medline

da Silva TF, Eira J, Lopes AT, Malheiro AR, Sousa V, Luoma A, Avila RL, Wanders RJ, Just WW, Kirschner DA, Sousa MM, Brites P (2014) Peripheral nervous system plasmalogens regulate Schwann cell differentiation and myelination. J Clin Invest 124:2560-2570. CrossRef Medline

Duque-Afonso J, Wei MC, Lin CH, Feng J, Buechele C, Wong SH, Bassik NC, and Cleary ML (2015) Oncogenic role for the Lck/ZAP70/PLCG2 signaling pathway in pre-B-ALL pathogenesis. Blood 126:810.

Fenster CP, Chisnell HK, Fry CR, Fenster SD (2010) The role of CD4dependent signaling in interleukin-16 induced c-Fos expression and facilitation of neurite outgrowth in cerebellar granule neurons. Neurosci Lett 485:212-216. CrossRef Medline

Forciniti L, Ybarra J 3rd, Zaman MH, Schmidt CE (2014) Schwann cell response on polypyrrole substrates upon electrical stimulation. Acta Biomaterialia 10:2423-2433. CrossRef Medline

Furió-Tarí P, Tarazona S, Gabaldón T, Enright AJ, Conesa A (2016) spongeScan: A web for detecting microRNA binding elements in lncRNA sequences. Nucleic Acids Res 44:W176-W180. CrossRef Medline

Geisler S, Coller J (2013) RNA in unexpected places: long non-coding RNA functions in diverse cellular contexts. Nat Rev Mol Cell Biol 14:699-712. CrossRef Medline

Heinen A, Lehmann HC, Küry P (2013) Negative regulators of Schwann cell differentiation-novel targets for peripheral nerve therapies? J Clin Immunol 33:S18-S26. CrossRef Medline

Kallen AN, Zhou XB, Xu J, Qiao C, Ma J, Yan L, Lu L, Liu C, Yi JS, Zhang H, Min W, Bennett AM, Gregory RI, Ding Y, Huang Y (2013) The imprinted H19 lncRNA antagonizes let-7 microRNAs. Mol Cell 52:101-112. CrossRef Medline

Liao Q, Liu C, Yuan X, Kang S, Miao R, Xiao H, Zhao G, Luo H, Bu D, Zhao H, Skogerbø G, Wu Z, Zhao Y (2011) Large-scale prediction of long non-coding RNA functions in a coding-non-coding gene co-expression network. Nucleic Acids Res 39:3864-3878. CrossRef Medline

Liu GY, Zhao GN, Chen XF, Hao DL, Zhao X, Lv X, Liu DP (2016) The long noncoding RNA Gm15055 represses Hoxa gene expression by recruiting PRC2 to the gene cluster. Nucleic Acids Res 44:2613-2627. CrossRef Medline

Mantuano E, Inoue G, Li X, Takahashi K, Gaultier A, Gonias SL, Campana WM (2008) The hemopexin domain of matrix metalloproteinase- 9 activates cell signaling and promotes migration of schwann cells by binding to low-density lipoprotein receptor-related protein. J Neurosci 28:1157111582. CrossRef Medline

Miranda KC, Huynh T, Tay Y, Ang YS, Tam WL, Thomson AM, Lim B, Rigoutsos I (2006) A pattern-based method for the identification of MicroRNA binding sites and their corresponding heteroduplexes. Cell 126: 1203-1217. CrossRef Medline

Moran VA, Perera RJ, Khalil AM (2012) Emerging functional and mechanistic paradigms of mammalian long non-coding RNAs. Nucleic Acids Res 40:6391-6400. CrossRef Medline

Pan B, Zhou HX, Liu Y, Yan JY, Wang Y, Yao X, Deng YQ, Chen SY, Lu L, Wei ZJ, Kong XH, Feng SQ (2017) Time-dependent differential expression of long non-coding RNAs following peripheral nerve injury. Int J Mol Med 39:1381-1392. CrossRef Medline

Perlin JR, Lush ME, Stephens WZ, Piotrowski T, Talbot WS (2011) Neuronal Neuregulin 1 type III directs Schwann cell migration. Development 138:4639-4648. CrossRef Medline

Quek XC, Thomson DW, Maag JL, Bartonicek N, Signal B, Clark MB, Gloss BS, Dinger ME (2015) lncRNAdb v2.0: expanding the reference database for functional long noncoding RNAs. Nucleic Acids Res 43:D168D173. CrossRef Medline

Qureshi IA, Mattick JS, Mehler MF (2010) Long non-coding RNAs in nervous system function and disease. Brain Res 1338:20-35. CrossRef Medline

Shen J, Zhang Y, Yu H, Shen B, Liang Y, Jin R, Liu X, Shi L, Cai X (2016) Role of DUSP1/MKP1 in tumorigenesis, tumor progression and therapy. Cancer Med 5:2061-2068. CrossRef Medline

Son YJ, Trachtenberg JT, Thompson WJ (1996) Schwann cells induce and guide sprouting and reinnervation of neuromuscular junctions. Trends Neurosci 19:280-285. CrossRef Medline

Sun J, Li W, Sun Y, Yu D, Wen X, Wang H, Cui J, Wang G, Hoffman AR, Hu JF (2014) A novel antisense long noncoding RNA within the IGF1R gene locus is imprinted in hematopoietic malignancies. Nucleic Acids Res 42: 9588-9601. CrossRef Medline

Tang S, Zhu J, Xu Y, Xiang AP, Jiang MH, Quan D (2013) The effects of gradients of nerve growth factor immobilized PCLA scaffolds on neurite outgrowth in vitro and peripheral nerve regeneration in rats. Biomaterials 34:7086-7096. CrossRef Medline

Tay Y, Kats L, Salmena L, Weiss D, Tan SM, Ala U, Karreth F, Poliseno L, Provero P, Di Cunto F, Lieberman J, Rigoutsos I, Pandolfi PP (2011) Coding-independent regulation of the tumor suppressor PTEN by competing endogenous mRNAs. Cell 147:344-357. CrossRef Medline

Torigoe K, Tanaka HF, Takahashi A, Awaya A, Hashimoto K (1996) Basic behavior of migratory Schwann cells in peripheral nerve regeneration. Exp Neurol 137:301-308. CrossRef Medline

Valente AJ, Yoshida T, Gardner JD, Somanna N, Delafontaine P, Chandrasekar B (2012) Interleukin-17A stimulates cardiac fibroblast proliferation and migration via negative regulation of the dual-specificity phosphatase MKP-1/DUSP-1. Cell Signal 24:560-568. CrossRef Medline

Verrier JD, Semple-Rowland S, Madorsky I, Papin JE, Notterpek L (2010) Reduction of Dicer impairs Schwann cell differentiation and myelination. J Neurosci Res 88:2558-2568. CrossRef Medline

Wakatsuki S, Araki T, Sehara-Fujisawa A (2014) Neuregulin-1/glial growth factor stimulates Schwann cell migration by inducing alpha 5 beta 1 integrin-ErbB2-focal adhesion kinase complex formation. Genes Cells 19:66-77. CrossRef Medline

Wang Y, Xu Z, Jiang J, Xu C, Kang J, Xiao L, Wu M, Xiong J, Guo X, Liu H (2013) Endogenous miRNA sponge lincRNA-RoR regulates Oct4, nanog, and Sox2 in human embryonic stem cell self-renewal. Dev Cell 25:69-80. CrossRef Medline

Wang J, Ma R, Ma W, Chen J, Yang J, Xi Y, Cui Q (2016) lncDisease: a sequence based bioinformatics tool for predicting lncRNA-disease associations. Nucleic Acids Res 44:e90 CrossRef Medline

Wilusz JE, Sunwoo H, Spector DL (2009) Long noncoding RNAs: functional surprises from the RNA world. Genes Dev 23:1494-1504. CrossRef Medline

Wu D, Murashov AK (2013) Molecular mechanisms of peripheral nerve regeneration: emerging roles of microRNAs. Front Physiol 4:55. CrossRef Medline

Wu P, Zuo X, Deng H, Liu X, Liu L, Ji A (2013) Roles of long noncoding RNAs in brain development, functional diversification and neurodegenerative diseases. Brain Res Bull 97:69-80. CrossRef Medline

Xiang JF, Yin QF, Chen T, Zhang Y, Zhang XO, Wu Z, Zhang S, Wang HB, Ge J, Lu X, Yang L, Chen LL (2014) Human colorectal cancer-specific CCAT1-L lncRNA regulates long-range chromatin interactions at the MYC locus. Cell Res 24:513-531. CrossRef Medline

Xu S, Ao J, Gu H, Wang X, Xie C, Meng D, Wang L, Liu M (2017) IL-22 Impedes the proliferation of Schwann cells: transcriptome sequencing and bioinformatics analysis. Mol Neurobiol 54:2395-2405. CrossRef Medline

Yang L, Froberg JE, Lee JT (2014) Long noncoding RNAs: fresh perspectives into the RNA world. Trends Biochem Sci 39:35-43. CrossRef Medline

Yao C, Wang J, Zhang H, Zhou S, Qian T, Ding F, Gu X, Yu B (2015) Long non-coding RNA uc.217 regulates neurite outgrowth in dorsal root ganglion neurons following peripheral nerve injury. Eur J Neurosci 42:1718 1725. CrossRef Medline

Yu B, Qian T, Wang Y, Zhou S, Ding G, Ding F, Gu X (2012) miR-182 inhibits Schwann cell proliferation and migration by targeting FGF9 and NTM, respectively at an early stage following sciatic nerve injury. Nucleic Acids Res 40:10356-10365. CrossRef Medline

Yu B, Zhou S, Wang Y, Qian T, Ding G, Ding F, Gu X (2012) miR-221 and miR-222 promote Schwann cell proliferation and migration by targeting LASS2 after sciatic nerve injury. J Cell Sci 125:2675-2683. CrossRef Medline

Yu B, Zhou S, Hu W, Qian T, Gao R, Ding G, Ding F, Gu X (2013) Altered 
long noncoding RNA expressions in dorsal root ganglion after rat sciatic nerve injury. Neurosci Lett 534:117-122. CrossRef Medline

Yu B, Zhou S, Yi S, Gu X (2015) The regulatory roles of non-coding RNAs in nerve injury and regeneration. Prog Neurobiol 134:122-139. CrossRef Medline

Yuan JH, Yang F, Wang F, Ma JZ, Guo YJ, Tao QF, Liu F, Pan W, Wang TT, Zhou CC, Wang SB, Wang YZ, Yang Y, Yang N, Zhou WP, Yang GS, Sun SH (2014) A long noncoding RNA activated by TGF-beta promotes the invasion-metastasis cascade in hepatocellular carcinoma. Cancer Cell 25: 666-681. CrossRef Medline

Zhang A, Xu M, Mo YY (2014) Role of the lncRNA-p53 regulatory network in cancer. J Mol Cell Biol 6:181-191. CrossRef Medline
Zhou S, Gao R, Hu W, Qian T, Wang N, Ding G, Ding F, Yu B, Gu X (2014) miR-9 inhibits Schwann cell migration by targeting Cthrcl following sciatic nerve injury. J Cell Sci 127:967-976. CrossRef Medline

Zhu C, Li J, Ding Q, Cheng G, Zhou H, Tao L, Cai H, Li P, Cao Q, Ju X, Meng X, Qin C, Hua L, Shao P, Yin C (2013) miR-152 controls migration and invasive potential by targeting TGF alpha in prostate cancer cell lines. Prostate 73:1082-1089. CrossRef Medline

Zhu XF, Shan Z, Ma JY, Wang M, Zhang CX, Liu RM, Wu WB, Shi YW, Li W, Wang SM (2015) Investigating the role of the post-transcriptional gene regulator MiR-24-3p in the proliferation, migration and apoptosis of human arterial smooth muscle cells in arteriosclerosis obliterans. Cell Physiol Biochem 36:1359-1370. CrossRef Medline 